\title{
Traumatic disruption of the sacral root sheath
}

\author{
G. PADBERG AND L. N. M. COENE \\ From the Departments of Neurology and Neurosurgery, \\ St Annadal Hospital, Maestricht, the Netherlands
}

SYNOPSIS An unusual case of sacral nerve root injury in a boy aged 6 years is described. Surgical intervention was not undertaken. Recovery of function was complete.

From perusal of the literature on trauma of nerve roots one discovers that the traumatic avulsion of cervical nerve roots is a well-known entity and that, because of the protection afforded by the bony pelvis, similar lesions in the lumbosacral region are rare.

As far as we are aware, only eight cases of lumbosacral nerve root injuries have been reported, all leading to the formation of root sleeve meningocele. The patients were young, had experienced a high momentum injury, and had, with one exception, fractures of the bony pelvis usually accompanied with leg fracture.

This report of a sacral nerve root injury is unusual in that the trauma was not severe, no fractures of the bony pelvis could be detected, and no meningocele developed. In addition, our patient is the youngest of those reported to date.

\section{CASE REPORT}

A 6 year old boy, during a rough and tumble with his 9 year old friend who was much stronger and bigger, fell down and lay on the floor on his left side. The older boy kept him down by sitting on him, thereafter jumping up and down two or three times on the patient's right side. The boys were separated and continued their play in a quieter manner. The next morning the patient could get out of bed only with great difficulty. His lower back was very painful and he could not walk because of pain in both legs. Treatment was instituted on the assumption that the pain was the result of muscle concussion. Radiographs of the spine, pelvis, and hip joints showed no abnormalities.

Because the boy did not improve he was admitted to hospital three weeks after the injury. His back

(Accepted 25 April 1975.) proved to be very rigid and was painful on palpation. Straight leg raising was hardly possible without aching sensations, more pronounced on the right side than on the left. There was no neurological deficit.

There were normal responses on EMG recording. Bladder function was intact. Intravenous pyelography yielded normal pictures. The cerebrospinal fluid was normal in composition.

A myelogram demonstrated rupture of the left first sacral root sheath and contrast material flowed freely from the subarachnoid space into the adjacent tissues. There was apparently no formation of a meningocele or dural sac (Fig. 1).

It was decided to treat the boy non-surgically. Two weeks after the myelography check radiographs revealed further diffuse distribution of the iophendylate (Myodil). The boy recovered very satisfactorily, did not complain of residual pain or stiffness and returned home four weeks after his admission. He was seen at regular times and remained feeling well.

Ten months after the injury a new series of radiographs demonstrated two small cysts, one in the sacral canal and the other of the right first sacral root sleeve (Fig. 2a, b). Although there was no strict clinical indication for repeat myelography, both parents insisted that the procedure should be carried out. On the second myelogram, ten months after the injury, one could still see the rupture of the left sacral root sheath but again there was no evidence of the formation of a meningocele (Fig. 2c). Another check radiograph showed that the distribution of the contrast material differed somewhat from that on the first myelogram, the whole of the sacral canal being filled with contrast material (Fig. 3). In the meantime, the boy remained well and experienced no sideeffects. One year after this second myelogram was carried out new radiographs were taken. They revealed that the greater part of the contrast material had disappeared, except for that in what were prob- 


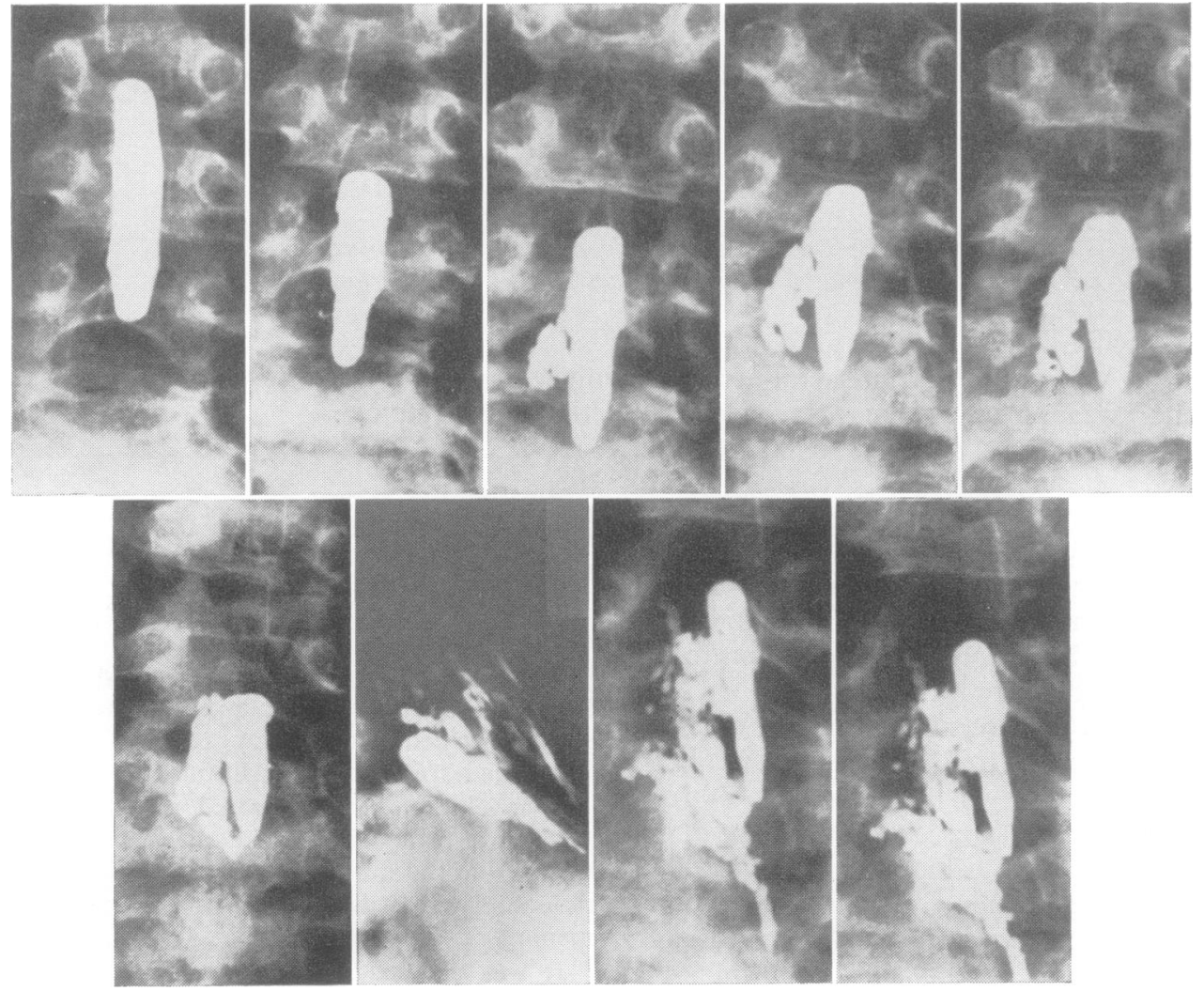

FIG. 1 Via lumbar punction $1.5 \mathrm{ml}$ iophendylate (Myodil) was injected. In prone position pictures were taken starting at the L3-L4 and L4-L5 interspaces. At the level of the left L5-S1 interspace the contrast material is beginning to leave the subarachnoid space (third picture).

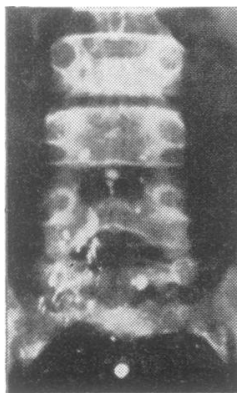

(a)

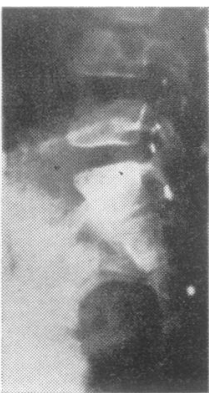

(b)

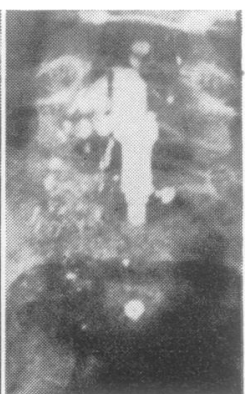

(c)

FIG. 2 Radiographs taken 10 months after the injury. The greater part of the Myodil has disappeared and two small cysts are visible (a) and (b). Repeat myelography (c) shows that again contrast material is leaving the subarachnoid space, though it is less in amount.

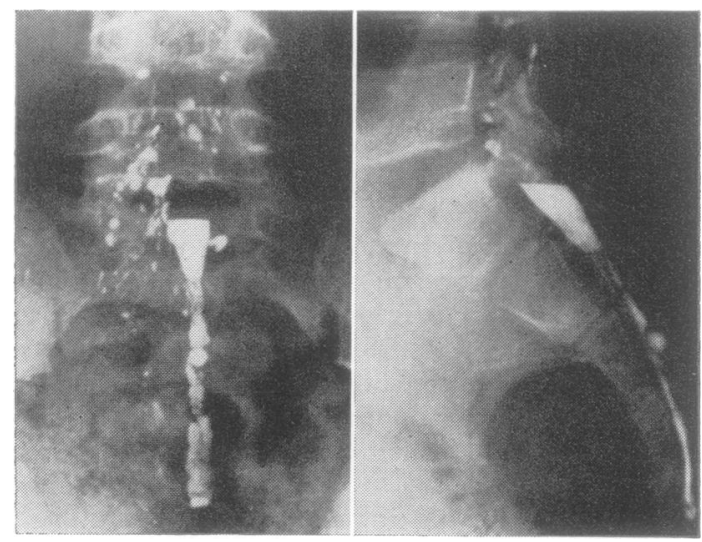

FIG. 3 Check radiographs taken three days after the repeat myelography. 
ably two cysts in the sacral canal and in the small cyst of the right first sacral root sleeve mentioned above.

The boy's health remains excellent. He has no complaints and neurological examination is negative.

\section{DISCUSSION}

The incidence of any nerve damage in patients with pelvic traumata is very low. Typical series quote $0.75 \%$ (Lam, 1936) and $1.2 \%$ (Patterson and Morton, 1961), though Noland and Conwell (1933) gave an incidence of $9 \%$.

Only eight well-documented cases of lumbosacral nerve root trauma with the myelographic findings have been reported (Finney and Wulfman, 1960 (one); Goodell, 1966 (two); Alker et al., 1967 (two); Payne and Thomson, 1969 (one); Carlson and Hoffman, 1971 (one); McLennan et al., 1973 (one)).

Lumbosacral root avulsion and meningeal tear are rare because of the protection afforded by the bony pelvis. Thus, if such a lesion occurs, there must be a history of severe pelvic trauma, usually accompanied by fracture of the pelvis, spine, or leg. However, individual differences in the extent of the trauma do exist. There are, in fact, two reports of cases in which no fractures were seen on the side of the lesion (Finney and Wulfman, 1960; Carlson and Hoffman, 1971).

It is postulated (White and Hanelin, 1954) that a meningocele could follow root sheath tear as a result of the effect of pulsatile cerebrospinal fluid in the cavity produced by the retracted distal stump of the nerve.

In our case, no fractures were seen, probably because the trauma was relatively mild. Though the exact mechanism of the injury in our patient is not known, we believe that the disruption was not the result of traction. It is far more likely that the root sheath was cut in the bony surroundings of the intervertebral foramen by the repeated jumps while the boy was lying on his left side. The absence of neurological deficit indicates an intact root with a disruption only of the sleeve so that no retraction of the distal stump ensued. This, together with the youth of the patient, could possibly account for the fact that only leakage of the cerebrospinal fluid followed and pulsatile forces were not strong enough to form a closed cavity. It could be questioned whether retraction of a distal stump is a necessary prerequisite to cavity formation. In two cases in which surgical intervention was undertaken, intact nerve roots at the level of the meningoceles were found (Goodell, 1966; Alker et al., 1967).

As regards the small cysts it is probable, based on the classification of Sutton (1963), that the two in the sacral canal are meningoceles and the third a perineural cyst. They could not be seen on the first series of radiographs but appeared on the later films.

Though several authors believe that such cysts are congenital in origin (Padberg, 1959, 19601961 ; Strully, 1956), there are other authors who attribute them to previous trauma (Schreiber and Haddad, 1951; Tarlov, 1953).

\section{REFERENCES}

Alker, G. J., Jr, Glasauer, F. E., and Zoll, J. G. (1967). Myelographic demonstration of lumbosacral nerve root avulsion. Radiology, 89, 101-104.

Carlson, D. H., and Hoffman, H. B. (1971). Lumbosacral traumatic meningocele. Neurology (Minneap.), 21, 174-176.

Finney, L. A., and Wulfman, W. A. (1960). Traumatic intradural lumbar nerve root avulsion with associated traction injury to the common peroneal nerve. American Journal of Roentgenology, 84, 952-957.

Goodell, C. (1966). Neurological deficits associated with pelvic fractures. Journal of Neurosurgery, 24, 837-842.

Lam, C. R. (1936). Nerve injury in fracture of the pelvis. Annals of Surgery, 104, 945-951.

McLennan, J. E., McLaughlin, W. T., and Skillicorn, S. A. (1973). Traumatic lumbar nerve root meningocele. Journal of Neurosurgery, 39, 528-532.

Noland, L., and Conwell, H. E. (1933). Fractures of the pelvis. Summary of treatment and results attained in 185 cases. Surgery, Gynecology and Obstetrics, 56, 522-525.

Padberg, G. (1959). Perineurale wortelkystes. Nederlands Tijdschrift voor Geneeskunde, 103, 2054-2057.

Padberg, G. (1960-1961). Perineural radicular cysts. In Year Book of Radiology, pp. 68-69. Year Book Publishers: Chicago, Ill.

Patterson, F. P., and Morton, K. S. (1961). Neurological complications of fractures and dislocations of the pelvis. Surgery, Gynecology and Obstetrics, 112, 702-706.

Payne, R. F., and Thomson, J. L. G. (1969). Myelography in lumbo-sacral plexus injury. British Journal of Radiology, 42, 840-845.

Schreiber, F., and Haddad, B. (1951). Lumbar and sacral cysts causing pain. Journal of Neurosurgery, 8, 504-509.

Strully, K. J. (1956). Meningeal diverticula of sacral nerve roots (perineurial cysts). Journal of the American Medical Association, 161, 1147-1152.

Sutton, D. (1963). Sacral cysts. Acta Radiologica (N.S.), 1, 787-795.

Tarlov, I. M. (1953). Sacral Nerve-root Cysts. Thomas: Springfield, Ill.

White, J. C., and Hanelin, J. (1954). Myelographic sign of brachial plexus avulsion. Journal of Bone and Joint Surgery, 36A, 113-118. 